\title{
A Review of Fatigue Life Prediction Method for Quayside Container Crane
}

\author{
Zhenjie $\mathrm{Xia}^{1}$, Weiping Ouyang ${ }^{2^{*}}$ and Yannan $\mathrm{Du}^{2}$ \\ ${ }^{1}$ Shanghai International Port (Group) Co.,Ltd. YiDong Container Terminal Branch, Shanghai, China \\ ${ }^{2}$ Shanghai Institute of Special Equipment Inspection and Technical Research, Shanghai, China \\ *Corresponding author
}

\begin{abstract}
Fatigue damage is the main damage cause of crane. The prediction method of fatigue life determines the design and service life of the crane. Therefore, it is extremely important to study the fatigue life prediction method of crane. In this paper, the existing fatigue life prediction methods are summarized systematically. Fatigue life research was involved in metal material, mechanics, vibration mechanics, fatigue theory, fracture mechanics and so on, which made a difference between the predicted result and the actual life. The emergence and application of new technologies promote the development of the fatigue life evaluation methods, but it still needs more study.
\end{abstract}

Keywords-fatigue; mechanics; probability statistics; new technology

\section{INTRODUCTION}

With the development of the world logistics industry, quayside container cranes as a large lifting equipment for improving the production capacity of loading and unloading operations are widely used in shipyards and ports, whose trends are large-scale, high-speed, automation and intelligence, high reliability, long life, low energy consumption and environmental protection[1]. Quayside container cranes as special equipment, safety accidents are happened frequently[2] At present, there are many quayside container cranes with hidden dangers in the port of china due to the historical problem. Fatigue is one of the main failure modes of the quayside container crane, and its destruction process needs to be accumulated, which may lead to grave consequences. Quayside container cranes use a large of welding structure. Welding position exists defects and stress concentration induced fatigue damage. It is a meaningful research on fatigue life prediction method for quayside container crane. In this paper, three existing parts used for fatigue life evaluation of quayside container cranes are discussed based on mechanics, probability statistics and intelligence technology.

\section{Prediction Method Based on Mechanics}

The prediction methods of fatigue life based on mechanics are one of most widely used method in engineering, which play an important role in the life prediction of cranes including prediction method based on the stress/strain [3, 4], accumulation of fatigue damage[5], fracture mechanics[6], damage mechanics[7,8] and energy[9]. The advantages and disadvantages of all kinds of life prediction method based on the mechanics are presented in Table 1 . Though the method based on the new theory may increased in precision of prediction, it exists some problems in engineering application such as complicated calculation, inadequate research and so on. Thus, different life prediction methods should be made a reasonable choice according to the actual situation. Mechanics method of forecasting precision mainly depends on the test and theory.

\section{Prediction Method Based on Probability STATISTICS}

The application of crane life assessment has been achieved[11,12]. In the conventional fatigue life calculation method, the parameters such as crack size, load and material characteristics are considered as deterministic quantities. However, these parameters are often indeterminate in engineering practice. The predicted fatigue life should be dispersible, and consistent with certain distribution characteristics. The dispersion and uncertainty problem could be solved by application of probability and statistics theory. Distribution of known parameters and the randomness of the parameters considering probability method is combined to get the remaining life included a certain reliability. Life prediction method based on probability could be merged with the method based on cumulative damage, or the method based on fracture mechanics. Probability model improves the reliability of traditional mechanical methods, but the reliability of the prediction results is limited by the sample size and the probabilistic model.

\section{Prediction Method Based on Intelligence TECHNOLOGY}

Traditional fatigue life prediction methods are mainly concentrated on the theory and experimental research, the qualitative or approximate quantitative prediction is achieved by the physical model and experiment. The practical engineering problems such as random, mutation and so on limit prediction accuracy.

Although the probability statistical methods could solve the practical random problem in a way, which is limited by the amount of data. Intelligence technology such as big data could solve these problems. It signals acquisition reflecting the structure performance changes, and uses new technology algorithms such as Neural Network, Expert System, Fuzzy Computing, Rough Set Theory, Evolutionary Algorithm and so on to predict fatigue life, which could be used for the more complex structures or environmental conditions[13,14]. However, prediction method based on intelligence technology needs more research due to the lack of application and optimizing. 
TABLE I. COMPARISON OF FATIGUE LIFE PREDICTION METHODS BASED ON MECHANICS[10]

\begin{tabular}{|c|c|c|c|}
\hline Theory & Definition & Advantage & Disadvantage \\
\hline Stress/Strain & $\begin{array}{l}\text { Use } \mathrm{S}-\mathrm{N} \text { or } \varepsilon-\mathrm{N} \text { curves to } \\
\text { predict fatigue life. }\end{array}$ & $\begin{array}{l}\text { Less material parameter } \\
\text { Simple analysis method } \\
\text { Rich data accumulation }\end{array}$ & $\begin{array}{l}\text { Strong empirical } \\
\text { Poor universality }\end{array}$ \\
\hline $\begin{array}{l}\text { Accumulation of } \\
\text { fatigue damage }\end{array}$ & $\begin{array}{l}\text { Use accumulation of fatigue } \\
\text { damage theory including linear } \\
\text { and nonlinear accumulation }\end{array}$ & $\begin{array}{l}\text { Consider the effect of } \\
\text { variable load } \\
\text { Mature method }\end{array}$ & $\begin{array}{l}\text { The influencing factors } \\
\text { cannot be fully considered }\end{array}$ \\
\hline $\begin{array}{l}\text { Fracture } \\
\text { mechanics }\end{array}$ & $\begin{array}{l}\text { Assuming that there exists } \\
\text { the defect in the material or } \\
\text { component. } \\
\text { If the stress intensity factor } \\
\text { reaches the critical value, the } \\
\text { fracture occurs. }\end{array}$ & $\begin{array}{c}\text { Consider fatigue crack } \\
\text { propagation } \\
\text { Explan reasonablely the } \\
\text { mechanism of fatigue crack } \\
\text { propagation }\end{array}$ & $\begin{array}{l}\text { Ignore the crack phase } \\
\text { The stress intensity } \\
\text { factor of complex structure } \\
\text { is difficult to calculate }\end{array}$ \\
\hline $\begin{array}{l}\text { Damage } \\
\text { mechanics }\end{array}$ & $\begin{array}{c}\text { Material internal damage } \\
\text { (micro cracks or micro holes,etc.) } \\
\text { happened under the action of } \\
\text { external loading could be } \\
\text { identified as a continuous } \\
\text { distribution of available } \\
\text { performance degradation caused } \\
\text { by the material and structure } \\
\text { damage variable. }\end{array}$ & $\begin{array}{l}\text { Used for strain fatigue and } \\
\text { fracture mechanics } \\
\text { Consider the initiation stage } \\
\text { of fatigue crack }\end{array}$ & $\begin{array}{l}\text { Complex analysis } \\
\text { process } \\
\text { Inadequate }\end{array}$ \\
\hline Energy & $\begin{array}{c}\text { Damage caused by different } \\
\text { load types coluld be unified with } \\
\text { damage parameters based on } \\
\text { energy }\end{array}$ & Uniform different damage & Inadequate \\
\hline
\end{tabular}

\section{CONCLUSION}

In this paper, the existing fatigue life prediction methods are summarized systematically. Fatigue life research was involved in metal material, mechanics, vibration mechanics, fatigue theory, fracture mechanics and so on, which made a difference between the predicted result and the actual life. Some conclusions are as follows:

(1) Life prediction methods based on the mechanics predict the remaining life by using the failure and the failure mechanism of dynamic characteristics, which is widely used in various industry.

(2) The life prediction methods based on probabilistic statistics could reflect the general rules and overall characteristics of mechanical product life, but a lot of experiment and data accumulation are needed.

(3) Life prediction methods based on intelligence technology compare with the life prediction method based on the mechanics, probability and statistics is the development trend in the future, which needs to be further research.

\section{REFERENCE}

[1] Xiao-Dong Wang. The type and characteristics of the container crane on the shore $[\mathrm{J}]$, Architectural Engineering Technology and Besign, 2016, (11):1173,1176.

[2] Report of the general administration of quality supervision and inspection on the state of safety of special equipment of China in 2016 [J], China Special Equipment Safety 2017, 33(4): 1-5.

[3] Tao Qian, The study of fatigue life simulation prediction method for high strength resistance spot weld joints based on average stress intensity factor, in, Hunan University, 2015.
[4] Da-Wei Tang.Fatigue strength analysis of crane' s welded drum axis based on hot spot stress method [J], Hoisting and Conveying Machinery, 2015, (6): 85-88.

[5] Yue-Gui Feng, Xiao-Lin Xie, Min-Ping Jia, et al. Research and application of crane fatigue life prediction method based on the sequential method[J], Hoisting and Conveying Machinery, 2013, (2): $1-5$.

[6] Bo Yan. Fatigue life prediction based on the crack propagation and its application in the crane metal structure [J], China High-Tech Enterprises, 2016, (36): 52-54.

[7] Xiao-Ning Fan, Ge-Ning Xu, Rui-Gang Yang. Fatigue life estimation method of crane based on the damage - fracture mechanics theory [J], China Safety Science Journal, 2011, 21(9): 58-63.

[8] Feng-Yu Yin, Guang Zeng, Ning-Ge Xu, et al. Fatigue crack and life assessment of crane box beam $[\mathrm{J}]$, Chinese Journal Of Construction Machinery, 2010, 08(3): 274-278.

[9] Nian-Li Lu, Wei-Gang Zhan. Fatigue Life Prediction of Crane Based on Equivalent Initial Flaw Size and Power Spectral Density [J], Journal of South China University of Technology(Natural Science Edition), 2014, 42(4): 118-123.

[10] Xiao-Li Zhang, Xue-Feng Chen, Bing Li, etc. Review of Life Prediction for Mechanical Major Equipments [J], Journal of Mechanical Engineering, 2011, 47(11): 100-116.

[11] Xing-Jian Dong, Hong-Guang Li, Guang Meng. Reliability analysis on wind-induced stochastic fatigue for quayside container crane [J], Journal of Vibration Engineering, 2013, 26(6): 901-907.

[12] Jia-Chang Zhai, Qing-Sheng He. fatigue strength reliability design and analysis of bridge crane welding beam [J], Construction Machinery, 1992, (10): 12-18.

[13] Kai Cheng, Bao-Jin Wang, Jun Yu. Research on management between big data and hoisting safetyt [J], China Science \& Technology Panorama Magazine, 2016, (8): 94-94.

[14] Xiao-Ning Fan, Ge-Ning Xu, Ai-Hong Wang. Evaluation Method of Remaining Fatigue Life for Crane Based on the Acquisition of the Equivalent Load Spectrum by the Artificial Neural Network [J], Journal of Mechanical Engineering, 2011, 47(20): 69-74. 